\title{
Diurnal rhythm of cerebrospinal fluid and plasma leptin levels related to feeding in non-lactating and lactating rats
}

\author{
S Asakuma, O Hiraku, Y Kurose, S Kobayashi and Y Terashima \\ Laboratory of Animal Nutrition, Faculty of Animal Science, Kitasato University, Towada-shi, Aomori 034-8628, Japan \\ (Requests for offprints should be addressed to Y Terashima; Email: terashim@vmas.kitasato-u.ac.jp)
}

\begin{abstract}
Leptin suppresses food intake and increases energy expenditure in the hypothalamus. Rats consume most of their daily food intake during the dark phase of the diurnal cycle. Lactating rats have increased food intake, but the involvement of leptin in the regulation of food intake in this physiological condition is not well understood. The present experiment was carried out to determine the circadian pattern of leptin concentrations in plasma and cerebrospinal fluid (CSF) in relation to the feeding behavior of non-lactating and lactating rats.

Female rats were maintained on a controlled lighting schedule (lights on between 0600 and $1800 \mathrm{~h}$ ) and the food intake of lactating rats was two- or threefold higher than that of non-lactating rats. In both groups, food intake
\end{abstract}

was three times greater in the dark phase $(P<0 \cdot 01)$ compared with the light phase. The plasma concentrations of leptin were lower $(P<0 \cdot 01)$ in lactating rats than non-lactating rats in both light and dark phases, but there were no differences in plasma leptin levels between light and dark phases. In contrast, and in both groups, the leptin concentrations in CSF were lower $(P<0 \cdot 01)$ in the dark phase than in the light phase. Leptin levels in CSF were lower $(P<0 \cdot 01)$ in lactating rats than in non-lactating rats. We conclude that a diurnal pattern of leptin levels within the brain (but not in plasma) reflects characteristics of feeding behavior in lactating and non-lactating rats.

Journal of Endocrinology (2004) 180, 283-286

\section{Introduction}

Lactation markedly increases the nutrient requirements of the mother in most mammals. Lactating animals increase their food intake in order to meet the increased nutrient demands. Food consumption in the rat usually occurs in the dark phase. Lactating rats increase their food intake several-fold mainly during the dark phase, as is the case for non-lactating rats (Barber et al. 1997). From the various observations, lactation might be expected to be a hypoleptinemic state, which drives or at least facilitates the hyperphagia (Brogan et al. 1999, Woodside et al. 2000). Nevertheless, the relationship between circulating leptin levels and feeding behavior remains unclear.

Leptin is a hormone, mainly secreted by white adipose tissue, which acts on the hypothalamus to decrease appetite (Friedman \& Halaas 1998). Leptin acts within the hypothalamus to inhibit the synthesis and secretion of neuropeptide Y (NPY), which is a powerful orexigenic peptide (Frankish et al. 1995). The hypothalamic content of NPY and NPY mRNA expression increase during lactation; this may be a consequence of an overriding effect of reduced inhibition of NPY neurons by leptin (Smith 1993). However, diurnal variation of the leptin content in the brain during lactation has yet to be examined.
It has also been shown that there is a marked rise in serum leptin levels during the night in non-lactating rats, and this nocturnal increase in leptin secretion was not observed in lactating rats. Thus, it is proposed that the link between nocturnal food intake and increased serum leptin levels is broken during lactation and hypoleptinemia may be an important factor in promoting the hyperphagia of lactation (Pickavance et al. 1998). Peripherally produced leptin may enter the brain by binding to the choroid plexus (Devos et al. 1996) before being transported into the cerebrospinal fluid (CSF) by a saturable mechanism (Banks et al. 1996, Caro et al. 1996), to act in the regulation of feed intake in the hypothalamus. Accordingly, the leptin levels in CSF may directly reflect the feeding behavior of non-lactating and lactating rats. The extent to which central levels of leptin relate to diurnal patterns of feeding behavior is not known in lactating rats. The present study was conducted to determine plasma and CSF leptin concentrations in lactating rats and non-lactating rats.

\section{Materials and Methods}

Experimental animals and diets

This study used 13- to 14-week-old female Wistar rats (JAPAN CLEA, Tokyo, Japan) with an initial average 
body weight of approximately $230 \mathrm{~g}$. The animals were housed under controlled lighting (12 h light:12 h darkness, lights on at $0600 \mathrm{~h}$ ) and temperature $\left(22 \pm 2{ }^{\circ} \mathrm{C}\right)$ conditions with free access to food and water.

The control animals used in the experiment were non-lactating; they were virgin and in the diestrous stage of the estrous cycle. Lactating rats, of the same age as the controls, were housed singly with their litters. The litter size was adjusted to ten pups at birth. All animals had been adapted to standard powder meal (CE-2; $352 \mathrm{kcal} / 100 \mathrm{~g}$; JAPAN CLEA, Tokyo, Japan) for more than 2 weeks.

All procedures used in this study were performed in accordance with institutional guidelines for animal care at Kitasato University.

\section{Catheterization of the jugular vein}

Lactating rats underwent surgery at 3 days postpartum. Rats were anesthetized during the surgery by i.p. injection of pentobarbital sodium ( $40 \mathrm{mg} / \mathrm{kg}$ body weight). The right jugular vein was exposed as for i.v. injection. A catheter was prepared by cutting squarely across it with a scalpel blade to produce a blunt end. If the catheter was to be used only for administering substances then only a few millimeters needed to be within the blood vessel. After flushing with a small amount of $20 \mathrm{U}$ heparin-saline solution ensuring that no air entered the circulation, the catheter was finally filled with $300 \mathrm{U}$ heparin-saline solution and a suitable plastic cap was attached to a 23 -gauge needle on the end of the catheter.

\section{Food intake and blood sampling}

Food intake in lactating and non-lactating rats $(n=6)$ implanted with jugular venous catheters was measured at $6 \mathrm{~h}$ intervals for $24 \mathrm{~h}$, beginning at $0600 \mathrm{~h}$. Blood collections in lactating rats were performed on day 9 of lactation. Blood samples of $0.5 \mathrm{ml}$ were taken from the jugular vein at 0900, 1500, 2100 and $0300 \mathrm{~h}$. Plasma samples were stored at $-80{ }^{\circ} \mathrm{C}$ until assay.

\section{Cannulation of the cisterna magna}

The surgery for CSF sampling was performed as previously described (Sarna et al.1983, Huang et al. 1996). Lactating rats underwent surgery 3 days postpartum; cannulation of the cisterna magna was performed in addition to catheterization of the jugular vein. Rats were anesthetized with pentobarbital sodium ( $40 \mathrm{mg} / \mathrm{kg}$ body weight, i.p.). The anesthetized rat was positioned in a stereotaxic frame and the calvarium exposed via a midline incision. Briefly, a hole ( $2 \mathrm{~mm}$ diameter) was drilled in the midline $3 \mathrm{~mm}$ caudal to lambda under constant irrigation with sterile, buffered saline. A polyethylene tube (internal diameter $0.28 \mathrm{~mm}$, outer diameter $0.61 \mathrm{~mm}$; intracranial length 6-7 mm; PE-10, Becton Dickinson and Co., MD, USA) was inserted through the hole in the calvarium and gently forced epidurally along the internal surface of the occipital bone into the cisterna magna and fixed to the bone with dental cement (GC Corporation, Tokyo, Japan).

\section{CSF sampling}

The rats were freely moving during the sampling of CSF on day 9 of lactation and non-lactation. The CSF samples were taken at $0900 \mathrm{~h}$ (minimum consumption phase of food intake) and $2100 \mathrm{~h}$ (maximum consumption phase of food intake); samples were frozen immediately and kept at $-80{ }^{\circ} \mathrm{C}$ until analyzed.

\section{Sample analyses}

Leptin concentrations in plasma $(10 \mu \mathrm{l})$ and CSF $(50 \mu \mathrm{l})$ were determined using the Rat Leptin ELISA kit (Yanaihara Institute Inc., Shizuoka, Japan). The assay sensitivity was $78.1 \mathrm{pg} / \mathrm{ml}$. The inter- and intra-assay coefficients of variation were $3 \cdot 2-5 \cdot 6$ and $3 \cdot 5-5 \cdot 9 \%$ respectively.

\section{Statistical analyses}

Results were analysed by two-way ANOVA with two physiological states (lactating and non-lactating) and two photoperiods (light and dark). Significant differences between each value were tested using Fisher's PLSD. Data are reported as means \pm S.E.M.

\section{Results}

\section{Food intake}

Food intakes in lactating rats were greater $(P<0 \cdot 01)$ than in non-lactating rats (Fig. 1). Food consumption of both lactating and non-lactating rats was greater $(P<0 \cdot 01)$ in the dark phase than in the light phase. Lactating rats ate two or three times more $(P<0 \cdot 01)$ than non-lactating rats in each of the four periods sampled, as shown in Fig. 1.

\section{Plasma leptin concentrations}

Plasma leptin levels were lower $(P<0 \cdot 01)$ in lactating rats than in non-lactating rats (Fig. 2). Significant differences $(P<0.01)$ in leptin levels between lactating and nonlactating were observed at 0300 and 0900 h. Plasma leptin concentrations in both physiological states remained relatively constant during the light and dark phases

\section{CSF leptin concentrations}

Overall CSF leptin concentrations in lactating rats were significantly decreased $(P<0.01)$ compared with those in non-lactating rats (Fig. 3). CSF leptin levels were lower $(P<0 \cdot 01)$ during the dark phase than in the light phase in 


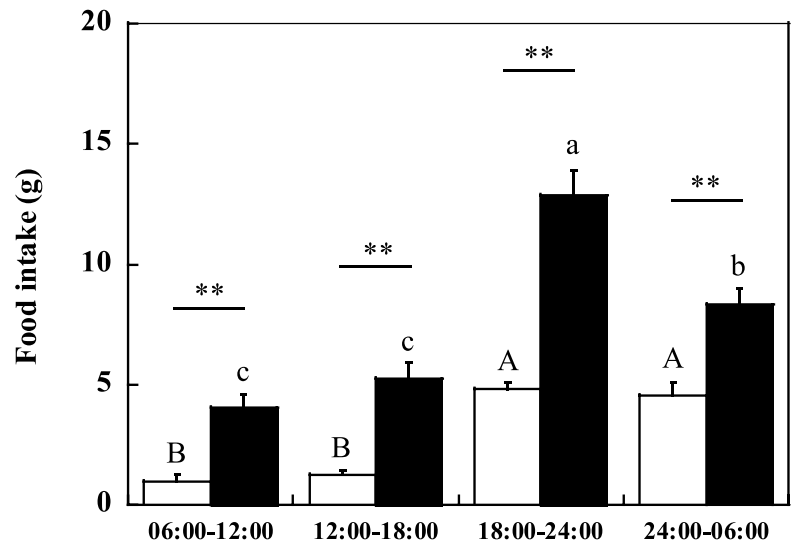

Figure 1 Food intake in non-lactating rats (open bar, $n=6$ ) and lactating rats (solid bar, $n=6$ ). Mean values are shown and vertical lines represent the S.E. The effect of physiological state on food intake was significant $(P<0 \cdot 01)$. Means with different superscripts are significantly different within a physiological state $(\mathrm{a}, \mathrm{b}$ and $\mathrm{C}$, $P<0.01 ; A$ and $B, P<0.01)$. The effect of photoperiod on food intake was significant $(P<0 \cdot 01) .{ }^{*}$ Significant differences between physiological states in each period, $P<0 \cdot 01$.

both groups. In the light phase, CSF leptin concentrations in lactating rats were significantly lower $(P<0.01)$ than in non-lactating rats.

\section{Discussion}

Our results show that plasma leptin levels are reduced in lactating rats compared with non-lactating controls, though the diurnal change of circulating leptin did not reflect the pattern of feeding behavior. The reduced levels

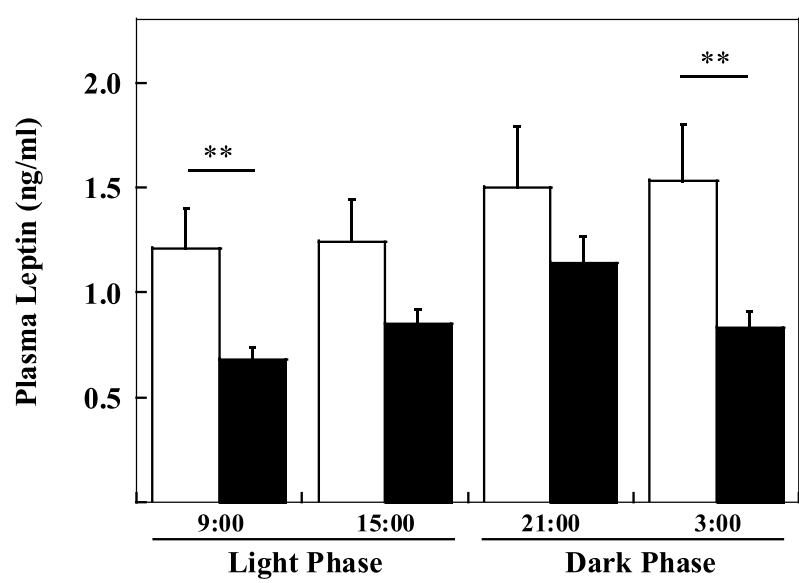

Figure 2 The circadian rhythm of plasma leptin concentrations for one day in non-lactating (open bar, $n=6$ ) and lactating rats (solid bar, $n=6$ ) with ad libitum feeding. Mean values are shown and vertical lines represent the S.E. The effect of physiological state on plasma leptin levels was significant $(P<0 \cdot 01)$ but the effect of photoperiod on plasma leptin concentrations was not significant.

**Significant differences between physiological states in each time period, $P<0 \cdot 01$.

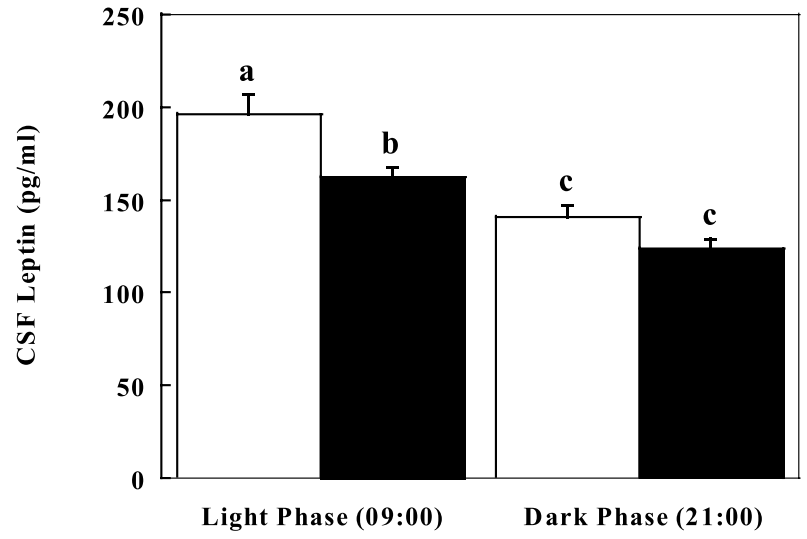

Figure 3 Effect of lactation on diurnal changes in leptin concentrations in CSF. CSF samples were collected from the cisterna magna of freely moving non-lactating (open bar, $n=7$ ) and lactating rats (solid bar, $n=7$ ) at $0900 \mathrm{~h}$ (light phase) and $2100 \mathrm{~h}$ (dark phase). Mean values are shown and vertical lines represent the S.E. The effect of physiological state on CSF leptin concentrations was significant $(P<0 \cdot 01)$ and the effect of photoperiod on CSF leptin levels was also significant $(P<0 \cdot 01)$. Means with different superscripts are significantly different $(a, b$ and $\mathrm{C}, P<0 \cdot 01)$.

of circulating leptin in lactating rats may contribute to the massive hyperphagia observed during lactation. In several studies, serum leptin decreased during early lactation to values lower than those found in virgin rats (Johnstone \& Higuchi 2001). If peripheral leptin directly affects food intake, circulating levels of leptin should decrease during the dark phase. However, plasma leptin has been generally found to increase at night, the period when rats consume most of their food. Some studies have shown diurnal changes in the amount of leptin mRNA in adipose tissue in male rats fed ad libitum, with maximum levels at night and minimum levels during the daytime (Pickavance et al. 1998). Therefore, we tested the hypothesis that the variation in CSF leptin levels, rather than plasma leptin levels, would affect the characteristics of feeding behavior in rats. Overall CSF leptin concentrations in lactating rats were lower than those in non-lactating rats. CSF leptin levels in lactating and non-lactating rats were substantially lower during the dark phase compared with the light phase. Thus, the present results confirm that a diurnal pattern of change in CSF leptin concentrations reflects characteristics of feeding behavior in both lactating and non-lactating rats.

In the present study, CSF leptin levels in both groups of rats were significantly lower in the dark phase than in the light phase. In contrast, plasma leptin levels tended to increase during the dark phase in lactating and nonlactating rats. In other words, the variation of CSF leptin concentrations did not parallel changes in plasma leptin levels. The inconsistency between blood and CSF leptin concentrations may be due to the permeability of 
leptin at the blood-brain barrier (BBB). In some cases of obesity, food intake is not inhibited even if blood leptin levels increase and this is thought to be due to the failure of leptin to enter the hypothalamus (Lynn et al. 1996, Kastin et al. 1999). For a hormone to reach most sites within the brain, it must cross the $\mathrm{BBB}$. There is a unidirectional saturable transport system across the $\mathrm{BBB}$ for leptin (Maness et al. 1998, Zlokovic et al. 2000). A recent report has suggested that the expression of short isoforms of leptin receptors, especially Ob-Ra, play a role in transporting circulating leptin to the hypothalamus (Bjørbæk et al. 1998). Impairment of the transport of leptin across the $\mathrm{BBB}$ has been considered to be responsible for the obesity and the pregnancy referred to as "leptin resistance' (Wu-Peng et al. 1997).

Overall CSF leptin levels, as well as plasma leptin levels, were lower in lactating rats compared with non-lactating controls. Degradation of blood leptin may cause a fall in CSF leptin levels in lactation, although there is no research on the resolution of plasma leptin. There was no significant difference in circulating leptin levels between light and dark phases in the present study, nevertheless the circadian rhythm of CSF leptin concentrations in lactating and non-lactating rats was also observed, with low concentrations in the dark phase and high concentrations in the light phase. Thus, the variation of CSF leptin suggests that $\mathrm{Ob}-\mathrm{R}$ a receptor expression, related to leptin transport at the $\mathrm{BBB}$, might have circadian rhythm in both lactating and non-lactating rats. A recent study has shown that expression of the $\mathrm{Ob}-\mathrm{Ra}$ gene in the hypothalamus is unaltered by lactation (Denis et al. 2003), however Ob-Ra receptor expression might have circadian rhythm in limited areas, such as the $\mathrm{BBB}$ in lactating and nonlactating rats.

In conclusion, we have demonstrated for the first time that, although there is no diurnal variation in plasma levels of leptin, there is a diurnal pattern in the concentrations in the CSF. This may relate to the pattern of feeding behavior in rats.

\section{Acknowledgements}

The authors are very grateful to Professor Iain Clark and Dr Javed Iqbal of Prince Henry's Institute of Medical Research, Australia for their kind advice on the manuscript. We thank Yuki Ogawa, Yukiko Saito, Michiko Sasaki and Sachiko Watanabe for skilled technical assistance.

\section{References}

Banks WA, Kastin AJ, Weitao H, Jaspan JB \& Maness LM 1996 Leptin enters the brain by saturable system independent of insulin. Peptides 17 305-311.

Barber MC, Clegg RA, Travers MT \& Vernon RG 1997 Lipid metabolism in lactating mammary gland. Biochimica et Biophysica Acta 1347 101-126.
Bjørbæk C, Elmquist JK, Michl P, Ahima RS, Bueren A, Mccall AL \& Flier JS 1998 Expression of leptin receptor isoforms in rat brain microvessels. Endocrinology 139 3485-3491.

Brogan RS, Mitchell SE, Trayhurn P \& Smith MS 1999 Supression of leptin during lactation: contribution of the suckling stimulus versus milk production. Endocrinology 140 2621-2627.

Caro JF, Kolaczynski JW, Nyce MR, Ohannesian JP, Opennesian JP, Opentanova I, Goldman WH, Lynn RB, Zhang PL, Sinha MK \& Considine RV 1996 Decreased cerebrospinal-fluid/serum leptin ratio in obesity: a possible mechanism for leptin resistance. Lancet 348 140-141.

Denis RGP, Bing C, Naderali EK \& Vernon RG 2003 Lactation modulates diurnal expression profiles of specific leptin receptor isoforms in the rat hypothalamus. Journal of Endocrinology 178 225-232.

Devos R, Richards JG, Campfield LA, Tartaglia LA, Guisez Y, Van der Heyden J, Travernier J, Plaetinck G \& Burn P 1996 OB protein bind specifically to the choroids plexus of mice and rats. PNAS 93 5668-5673.

Frankish HM, Dryden S, Hopkins D, Wang Q \& Williams G 1995 Neuropeptide Y, the hypothalamus, and diabetes: insights into the central control of metabolism. Peptides 16 757-771.

Friedman JM \& Halaas JL 1998 Leptin and regulation of body weight in mammals. Nature 395 763-770.

Huang YL, Saljo A, Suneson A \& Hansson HA 1996 Comparison among different approaches for sampling cerebrospinal fluid in rats. Brain Research Bulletin 41 273-279.

Johnstone LE \& Higuchi T 2001 Food intake and leptin during pregnancy and lactation. Progress in Brain Research 133 215-227.

Kastin AJ, Pan W, Maness LM, Koletsky RJ \& Ernsberger P 1999 Decreased transport of leptin across the blood-brain barrier in rats lacking the short form of the leptin receptor. Peptides $\mathbf{2 0}$ 1449-1453.

Lynn RB, Cao G, Considine RV, Hyde TM \& Caro JF 1996 Autoradiographic localization of leptin binding in the choroid plexus of $\mathrm{ob} / \mathrm{ob}$ and $\mathrm{db} / \mathrm{db}$ mice. Biochemical and Biophysical Research Communications 219 884-889.

Maness LM, Kastin AJ, Farrell CL \& Banks WA 1998 Fate of leptin after intracerebroventricular injection into the mouse brain. Endocrinology 139 4556-4562.

Pickavance L, Tadayyon M, Williams G \& Vernon RG. 1998 Lactation suppresses diurnal rhythm of serum leptin. Biochemical and Biophysical Research Communications 248 196-199.

Sarna GS, Hutson PH, Tricklebank MD \& Curzon G 1983 Determination of brain 5-hydroxytryptamine turnover in freely moving rats using repeated sampling of cerebrospinal fluid. Journal of Neurochemistry 40 383-388.

Smith MS 1993 Lactation alters neuropeptide-Y and proopiomelanocortin gene expression in the arcuate nucleus of the rat. Endocrinology 133 1258-1265.

Woodside B, Abizaid A \& Jafferali S 1998 Effect of acute food deprivation on lactational infertility in rats is reduced by leptin administration. American Journal of Physiology 274 R1653-R1658

Wu-Peng XS, Chua SC, Okada N, Liu S, Nicolson M \& Leibel RL 1997 Phenotype of the obese Koletsky (fa) rat due to tyr763 stop mutation in the extracellular domain of the leptin receptor (lepr). Evidence for deficient plasma-to-CSF transport of leptin in both the Zucker and Koletsky obese rat. Diabetes 46 513-518.

Zlokovic BV, Jovanovic S, Miao W, Samara S, Verma S, \& Farrell CL 2000 Differential regulation of leptin transport by the choroid plexus and blood-brain barrier and high affinity transport systems for entry into hypothalamus and across the blood-cerebrospinal fluid barrier. Endocrinology 141 1434-1441.

Received 26 July 2003

Accepted 22 October 2003 